\title{
Effect of Heat Treatment Time on Dy-Cu Alloy Diffusion Process in Dy-Containing Commercial Nd-Fe-B Sintered Magnets
}

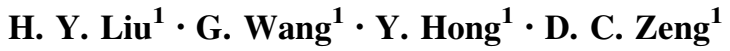

Received: 1 March 2017/Revised: 31 May 2017/Published online: 13 October 2017

(C) The Chinese Society for Metals and Springer-Verlag GmbH Germany 2017

\begin{abstract}
In this paper, the grain boundary diffusion process (GBDP) using a $\mathrm{Dy}_{70} \mathrm{Cu}_{30}$ (at.\%) alloy as the diffusion source was performed in a commercial sintered $\mathrm{Nd}-\mathrm{Fe}-\mathrm{B}$ magnet, and the effect of heat treatment time on the microstructure and magnetic properties of the magnet was investigated in detail. For the processed magnets heat-treated at $860{ }^{\circ} \mathrm{C}$, as heat treatment time increased, the coercivity and the depth of $(\mathrm{Nd}, \mathrm{Dy})_{2} \mathrm{Fe}_{14} \mathrm{~B}$ core-shell structure increased first and then decreased. However, when the heat treatment time was more than $2 \mathrm{~h}$, the diffusion path of Dy from the Dy-rich shell phase into the $\mathrm{Nd}_{2} \mathrm{Fe}_{14} \mathrm{~B}$ grains was revealed, and a nearly homogeneous ( $\left.\mathrm{Nd}, \mathrm{Dy}\right)_{2} \mathrm{Fe}_{14} \mathrm{~B}$ phase was formed, which brought on the decrease in both the depth of visible core-shell structure and the coercivity of $\mathrm{Nd}-\mathrm{Fe}-\mathrm{B}$ magnet.
\end{abstract}

\section{KEY WORDS: Sintered Nd-Fe-B magnets; Grain boundary diffusion; Heat treatment time; Coercivity; Micromagnetic simulation}

\section{Introduction}

Since their invention in 1983 [1, 2], sintered Nd-Fe-B magnets have been applied in a wide variety of fields, including information technology, consumer appliances, and magnetic resonance imaging, due to their outstanding magnetic properties. In order to meet the requirements for high-temperature applications, such as the traction motors of hybrid electric vehicles and wind generators, many studies have been devoted to further improvement in their functional properties, especially coercivity and thermal stability.

In recent years, the grain boundary diffusion process (GBDP) has emerged as a new method to increase the

Available online at http://link.springer.com/journal/40195

G. Wang

msgwang@scut.edu.cn

1 School of Materials Science and Engineering, South China University of Technology, Guangzhou 510640, China coercivity of $\mathrm{Nd}-\mathrm{Fe}-\mathrm{B}$ magnets with little sacrifice to the remanence. The GBDP in magnets has been investigated with many different diffusion sources, which can be in the form of pure metal [3, 4], oxides [5, 6], fluorides [6-8], hydrides $[9,10]$, and recently low melting point eutectic alloys [11-15]. Hot-deformed $\mathrm{Nd}-\mathrm{Fe}-\mathrm{B}$ [16], die-upset $\mathrm{Nd}-\mathrm{Fe}-\mathrm{B}[17,18]$, and Dy-free $\mathrm{Nd}-\mathrm{Fe}-\mathrm{B}$ [12], usually having relatively low coercivity, were used as original magnets for the GBDP. It has been illustrated that the coercivity of GBDPed magnets can be improved remarkably by heat-treating at an optimal temperature.

However, the correlation between the magnetic properties and heat treatment time of GBDPed Nd-Fe-B magnets has not been established yet. Meanwhile, the growth potential of coercivity for Dy-containing magnets has remained uncharted until now. Therefore, in the present work, a low melting point Dy-Cu binary alloy was introduced to a Dy-containing commercial sintered Nd-Fe-B magnet. The microstructure and magnetic properties of GBDPed magnet were investigated, and the influence of the heat treatment time on the diffusion process was evaluated. Moreover, the morphology and chemical 
composition in the grain boundary region were characterized, and micromagnetic simulation based on the experimental data was carried out to elucidate the possible influencing mechanism for magnetic properties of diffusion-processed $\mathrm{Nd}-\mathrm{Fe}-\mathrm{B}$ sintered magnets.

\section{Experimental Procedure}

Starting material of the sintered $\mathrm{Nd}-\mathrm{Fe}-\mathrm{B}$ magnet with a composition of $\mathrm{Nd}_{24.28} \mathrm{Pr}_{3.07} \mathrm{Dy}_{1.30} \mathrm{~Tb}_{1.36} \mathrm{Fe}_{67.31} \mathrm{Co}_{1} \mathrm{Cu}_{0.12-}$ $\mathrm{Al}_{0.24} \mathrm{Nb}_{0.20} \mathrm{~B}_{4.7} \mathrm{Ga}_{0.1}$ (wt\%) obtained from a commercial source was cut into pieces of $5 \mathrm{~mm} \times 5 \mathrm{~mm} \times 3 \mathrm{~mm}$. The ingots used as diffusion source with the eutectic composition of $\mathrm{Dy}_{70} \mathrm{Cu}_{30}$ (at.\%) were prepared by vacuum arc melting. Then, the Dy-Cu alloy ribbons were prepared by melt-spinning technique using the high vacuum quenching system with a copper roller speed about $45 \mathrm{~m} / \mathrm{s}$. The alloy ribbons were with a particle size of about $200 \mu \mathrm{m}$. The original magnets, wrapped with the eutectic alloy powders, were put into a quartz tube and were heat-treated at different temperatures $\left(800-880{ }^{\circ} \mathrm{C}\right)$ for different time (1-4 h) followed by the subsequent annealing at $500{ }^{\circ} \mathrm{C}$ for $1 \mathrm{~h}$ under the protection of high-purity argon. The diffusing temperatures were carefully selected to ensure that the $\mathrm{Dy}_{70} \mathrm{Cu}_{30}$ alloy was melted.

The magnetic properties of original and GBDPed magnets were analyzed using a physical property measurement system (PPMS-9, Quantum Design Co.). The microstructures were characterized by field emission scanning electron microscopy (FESEM, Nano430, FEI Co.). Energydispersive X-ray spectroscopy (EDS) was conducted to analyze the distribution of present elements. X-ray diffraction (XRD) analysis was carried out on a PANalytical X-ray diffractometer (X'Pert Pro) using $\mathrm{Cu} K_{\alpha}$ radiation. The melting point of $\mathrm{Dy}_{70} \mathrm{Cu}_{30}$ was determined by analyzing the differential scanning calorimetry (DSC) curve, which was measured from room temperature to $850{ }^{\circ} \mathrm{C}$ at a heating rate of $10{ }^{\circ} \mathrm{C} / \mathrm{min}$.

In the micromagnetic simulation, the magnetization state was calculated by solving the Landau-Lifshitz-Gilbert (LLG) equation using the OOMMF software [19]. A rectangular mesh of $2 \mathrm{~nm} \times 2 \mathrm{~nm} \times 2 \mathrm{~nm}$ was adopted, and the parameters of $\mathrm{Nd}_{2} \mathrm{Fe}_{14} \mathrm{~B} \quad\left(K_{1}=4.5 \mathrm{MJ} / \mathrm{m}^{3}\right.$, $\left.J_{\mathrm{s}}=1.61 \mathrm{~T}, A=12.5 \mathrm{pJ} / \mathrm{m}\right)$ and $\mathrm{Dy}_{2} \mathrm{Fe}_{14} \mathrm{~B}\left(K_{1}=4.2 \mathrm{MJ} /\right.$ $\mathrm{m}^{3}, J_{\mathrm{s}}=0.712 \mathrm{~T}, A=12.5 \mathrm{pJ} / \mathrm{m}$ ) were obtained from the work of Sagawa et al. [20] and Hirosawa et al. [21], respectively.

\section{Results}

\subsection{Diffusion Source}

$\mathrm{Dy}_{70} \mathrm{Cu}_{30}$ alloy was selected as the diffusion source in this study. The introduction of Dy enhances the magnetocrystalline anisotropy of the $\mathrm{Nd}_{2} \mathrm{Fe}_{14} \mathrm{~B}$ compound in the extensive layers of the $\mathrm{Nd}_{2} \mathrm{Fe}_{14} \mathrm{~B}$ grains where magnetization reversal starts. $\mathrm{Cu}$ in the intergranular phase can contribute to the improvement in wettability between intergranular phase and matrix phase. $\mathrm{Dy}_{70} \mathrm{Cu}_{30}$ is a eutectic alloy consisting of two phases, intermetallic $\mathrm{DyCu}$ and solid solution $\beta$-Dy, at room temperature. Figure 1a shows XRD pattern of the $\mathrm{Dy}_{70} \mathrm{Cu}_{30}$ alloy ribbons prepared in this study. Peaks corresponding to two phases (intermetallic $\mathrm{DyCu}$ and solid solution $\beta$-Dy) are observed. Figure $1 \mathrm{~b}$ shows the DSC curve of the $\mathrm{Dy}_{70} \mathrm{Cu}_{30}$ alloy ribbons, showing the melting temperature of eutectic mixture at $800{ }^{\circ} \mathrm{C}$.

\subsection{Magnetic Properties}

Figure 2a shows the coercivity values at $27{ }^{\circ} \mathrm{C}$ of the reference magnets, which were subjected to the same heat treatment conditions without Dy-Cu diffusion. It can be clearly seen that all of the coercivity values of reference samples were below the initial value of the original magnet (the dotted line in Fig. 2b) and varied with the heat treatment temperature and heat treatment time. The coercivity at $27{ }^{\circ} \mathrm{C}$ of GBDPed magnets versus heat treatment time at different temperatures is shown in Fig. $2 b$. With the increase in heat treatment time, the coercivity of GBDPed magnets at 820,860 , and $880{ }^{\circ} \mathrm{C}$ firstly increased and then reached a maximum. Subsequently, the coercivity decreased quickly when the heat treatment time reached $4 \mathrm{~h}$. However, the coercivity was observed to initially decrease for samples at 800 and $840{ }^{\circ} \mathrm{C}$. The highest coercivity was obtained for diffusion-processed magnets with the $\mathrm{Dy}_{70} \mathrm{Cu}_{30}$ alloy with heat treatment at $860{ }^{\circ} \mathrm{C}$ for $2 \mathrm{~h}$ followed by $500{ }^{\circ} \mathrm{C}$ for $1 \mathrm{~h}$. This sample was selected for detailed microstructure investigations and was hereafter called as "diffusion-processed magnet." Figure 2c shows the demagnetization curves at $27^{\circ} \mathrm{C}$ for the original magnet, diffusion-processed magnet, and the magnet only heat-treated at $860{ }^{\circ} \mathrm{C} / 2 \mathrm{~h}+500{ }^{\circ} \mathrm{C} / 1 \mathrm{~h}$ without $\mathrm{Dy}-\mathrm{Cu}$ diffusion. The intrinsic coercivity of diffusion-processed magnet increased significantly compared with the original magnet. The coercivity of the diffusion-processed magnet rose to 1855 from $1566 \mathrm{kA} / \mathrm{m}$ of the original magnet, and the corresponding remanence dropped from 1.356 to 1.215 T. However, as shown in Fig. 2c, the coercivity of the magnet exposed only to the heat treatment was lower 

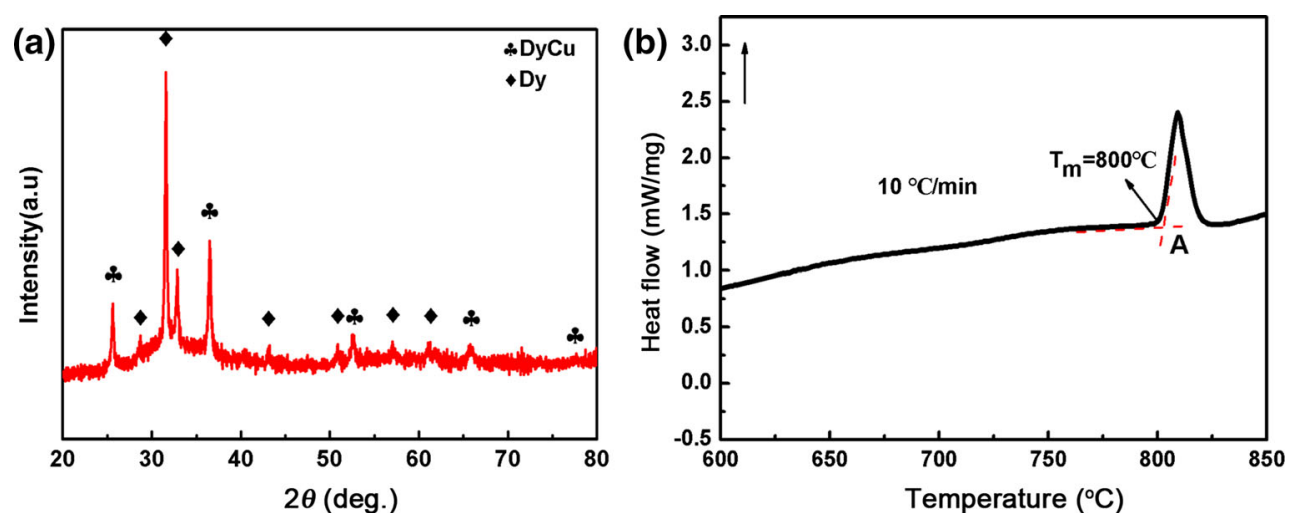

Fig. 1 a XRD pattern of the $\mathrm{Dy}_{70} \mathrm{Cu}_{30}$ alloy ribbons; $\mathbf{b} \mathrm{DSC}$ curve of the $\mathrm{Dy}_{70} \mathrm{Cu}_{30}$ alloy ribbons upon heating from room temperature to $850{ }^{\circ} \mathrm{C}$ at $10{ }^{\circ} \mathrm{C} / \mathrm{min}$
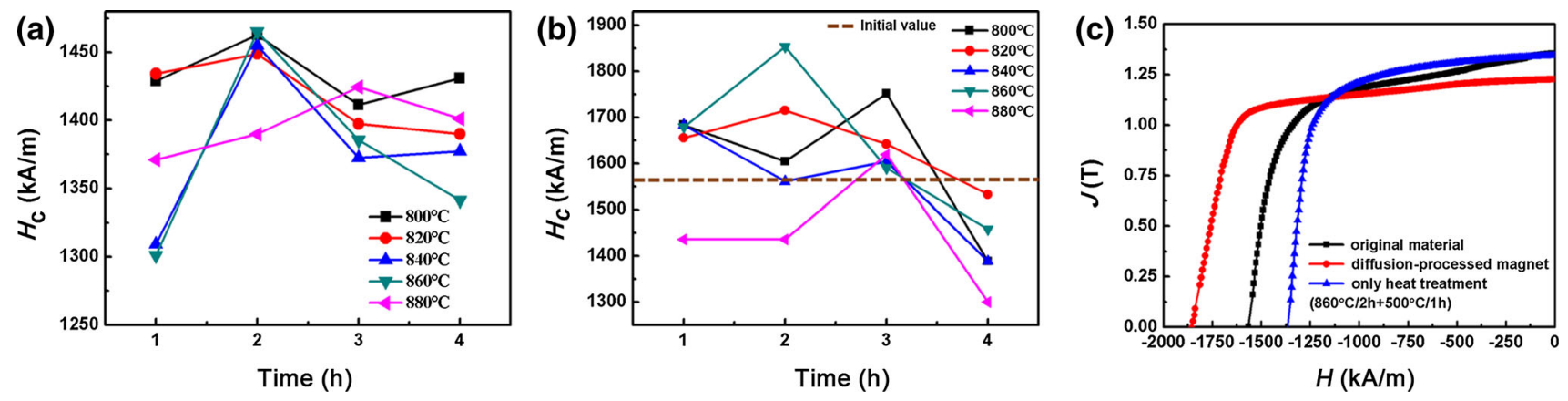

Fig. 2 a Coercivity values at $27{ }^{\circ} \mathrm{C}$ of the reference magnets exposed only to heat treatment without Dy-Cu diffusion, b Coercivity values at $27{ }^{\circ} \mathrm{C}$ of the GBDPed magnets under different heat treatment states, $\mathbf{c}$ demagnetization curves at $27^{\circ} \mathrm{C}$ for the original magnet, diffusionprocessed magnet using $\mathrm{Dy}_{70} \mathrm{Cu}_{30}$ alloy and the magnet only heat-treated at $860{ }^{\circ} \mathrm{C} / 2 \mathrm{~h}+500{ }^{\circ} \mathrm{C} / 1 \mathrm{~h}$ without Dy-Cu diffusion

than that of the original magnet. This result indicates that the reason for the enhancement of coercivity is the diffusion of $\mathrm{Dy}_{70} \mathrm{Cu}_{30}$ alloy rather than the heat treatment itself.

Magnetic properties and the temperature coefficients of remanence and coercivity between 20 and $120{ }^{\circ} \mathrm{C}$ are listed in Table 1. After the diffusion process, the temperature coefficient of remanence increased from $-0.110 \% /{ }^{\circ} \mathrm{C}$ to $-0.106 \% /{ }^{\circ} \mathrm{C}$ and the temperature coefficient of coercivity increased from $-0.563 \% /{ }^{\circ} \mathrm{C}$ to $-0.515 \% /{ }^{\circ} \mathrm{C}$ in the

Table 1 Magnetic properties at 20 and $120{ }^{\circ} \mathrm{C}$, temperature coefficient of remanence $(\alpha)$ and coercivity $(\beta)$ in the temperature range from 20 to $120{ }^{\circ} \mathrm{C}$ for the $\mathrm{Nd}-\mathrm{Fe}-\mathrm{B}$ magnets before and after $\mathrm{Dy}-\mathrm{Cu}$ diffusion treatment

\begin{tabular}{llllll}
\hline Magnetic properties & \multicolumn{2}{l}{ Original magnet } & & \multicolumn{2}{c}{ Diffusion-processed magnet } \\
\cline { 2 - 3 } \cline { 5 - 5 } \cline { 5 - 5 } & $20{ }^{\circ} \mathrm{C}$ & $120{ }^{\circ} \mathrm{C}$ & & $20{ }^{\circ} \mathrm{C}$ & $120{ }^{\circ} \mathrm{C}$ \\
\hline$H_{\mathrm{c}}(\mathrm{kA} / \mathrm{m})$ & 1636 & 715 & & 1937 & 940 \\
$J_{\mathrm{r}}(\mathrm{T})$ & 1.38 & 1.23 & & 1.222 & 1.093 \\
$(\mathrm{BH})_{\max }(\mathrm{MGOe})$ & 44.4 & 30.6 & & 34.4 & 26.09 \\
$\alpha\left(\% /{ }^{\circ} \mathrm{C}\right)$ & -0.110 & & -0.106 & \\
$\beta\left(\% /{ }^{\circ} \mathrm{C}\right)$ & -0.563 & -0.515 & \\
\hline
\end{tabular}

temperature range of $20-120{ }^{\circ} \mathrm{C}$. The diffusion-processed magnet had higher coercivity than the original magnet at 20 and $120{ }^{\circ} \mathrm{C}$. Thus, it is seen that the diffusion treatment for $\mathrm{Dy}_{70} \mathrm{Cu}_{30}$ alloy can also enhance the high-temperature properties and the temperature stability of the sintered $\mathrm{Nd}-$ $\mathrm{Fe}-\mathrm{B}$ magnets.

\subsection{Microstructure}

Figure 3 shows SEM images of the original magnet and the magnet exposed to only thermal treatment at $860{ }^{\circ} \mathrm{C} /$ $2 \mathrm{~h}+500{ }^{\circ} \mathrm{C} / 1 \mathrm{~h}$ without Dy-Cu diffusion. Both of them displayed the typical microstructure of sintered $\mathrm{Nd}-\mathrm{Fe}-\mathrm{B}$ magnet (shown in Fig. 3a, b), in which the dark gray $\mathrm{Nd}_{2} \mathrm{Fe}_{14} \mathrm{~B}$ grains contacted each other closely and Nd-rich phases mainly distributed in the triple junctions. Comparing these two images, we could not judge any differences between $\mathrm{Nd}_{2} \mathrm{Fe}_{14} \mathrm{~B}$ grains. The proportions of the rare-earth (RE)-rich phases enriched at triple junctions (the area outlined by red lines in Fig. 3) in the original magnet and the only heat-treated magnet were about $2.53 \%$ and $3.64 \%$, respectively. The microstructures in these two images were typical among most of the areas. The RE element in 

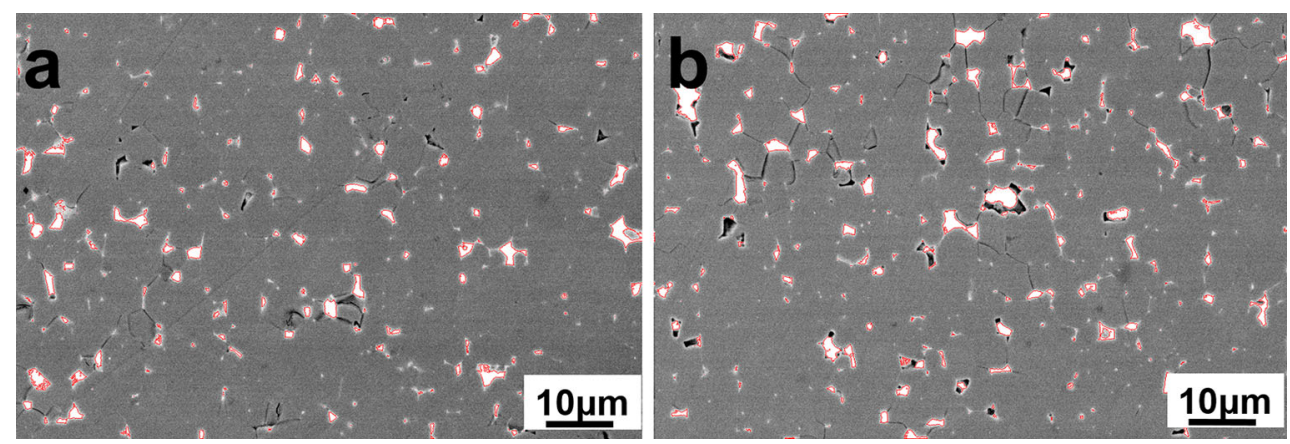

Fig. 3 SEM images of a the original magnet and $\mathbf{b}$ only heat-treated magnet at $860{ }^{\circ} \mathrm{C} / 2 \mathrm{~h}+500{ }^{\circ} \mathrm{C} / 1 \mathrm{~h}$ without Dy-Cu diffusion

expanded RE-rich phases might come from the layered grain boundary phases between the neighboring $\mathrm{Nd}_{2} \mathrm{Fe}_{14} \mathrm{~B}$ grains, and the reduction in decoupling effect would lead to deterioration of the coercivity for the magnet exposed to thermal treatment only.

Figure 4 illustrates the SEM images of the diffusionprocessed magnet at $860{ }^{\circ} \mathrm{C}$ for $1-4 \mathrm{~h}$. Compared to the microstructure of typical $\mathrm{Nd}-\mathrm{Fe}-\mathrm{B}$ sintered magnet, the GBDPed magnets with $\mathrm{Dy}-\mathrm{Cu}$ alloy presented distinct differences. The grains showed a remarkable $\mathrm{Nd}_{2} \mathrm{Fe}_{14} \mathrm{~B} /$ (Nd,Dy) ${ }_{2} \mathrm{Fe}_{14} \mathrm{~B}$ core-shell structure, and the thickness of the shells decreased with increasing distance from the magnet surface. However, the depth of the core-shell structure first increased with the increase in heat treatment time and reached a maximum of about $410 \mu \mathrm{m}$ at $2 \mathrm{~h}$, but slightly decreased with further increase in the heat treatment time.

A lot of microcracks could be found in the diffused samples shown in Fig. 4. We surmise that these microcracks might be induced by the shear cutting process during the preparation of SEM samples. However, it should be noted that the separated samples were adopted for the PPMS measurements after the GBDP without shear cutting, which can ensure that the magnetic properties we analyzed are accurate and reliable.

In order to investigate quantitatively the concentration distribution of Dy during the GBDP, three points of the Dyrich shell phase and the $\mathrm{Nd}_{2} \mathrm{Fe}_{14} \mathrm{~B}$ phase were analyzed by EDS, respectively, in the marked square regions in Fig. 4, and then, the mean value of each sample was calculated (shown in Fig. 5). The concentration of Dy in the region
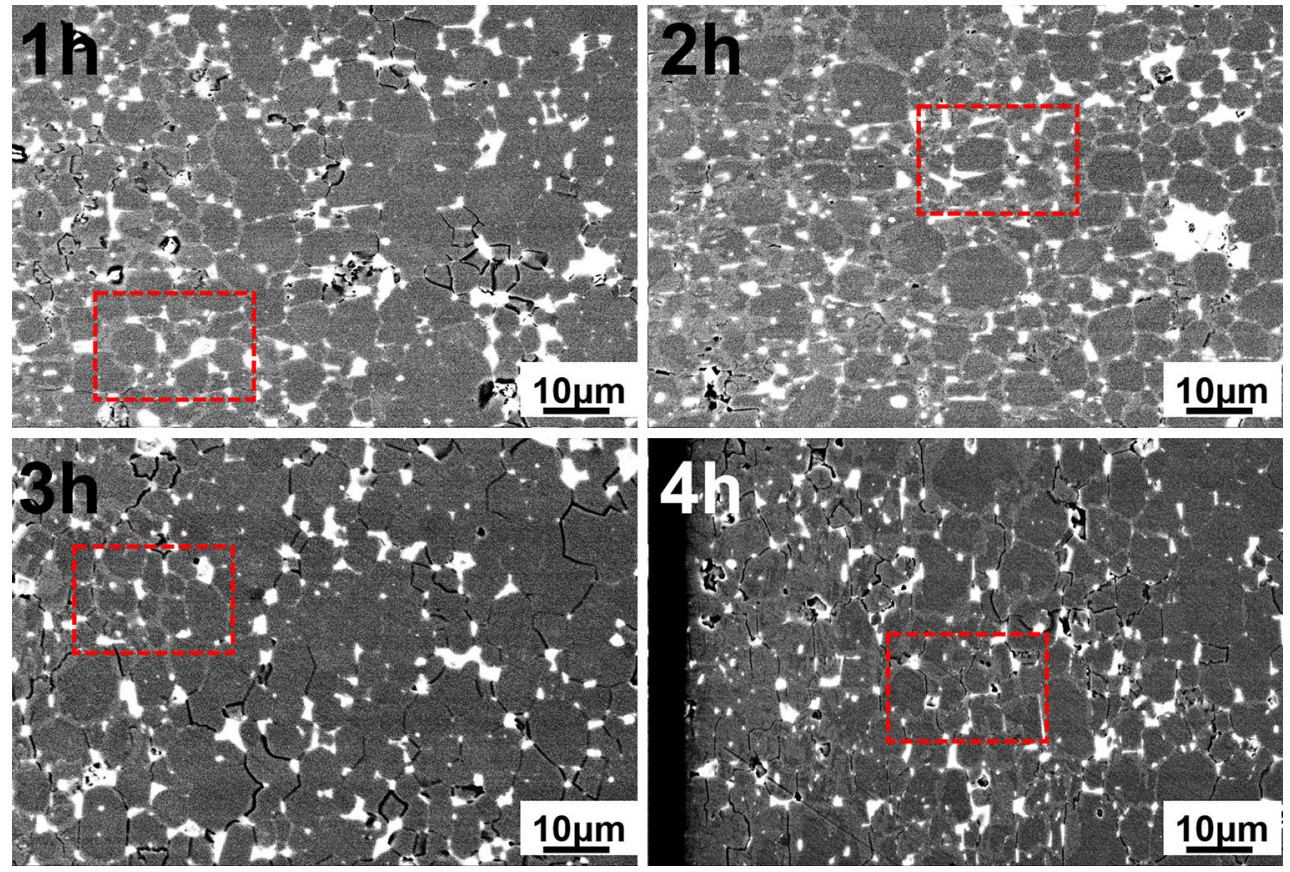

Fig. 4 SEM images of the diffusion-processed magnets at $860{ }^{\circ} \mathrm{C}$ for $1-4 \mathrm{~h}$, in which the distances from the right edge of each image to the magnet surfaces are $325 \mu \mathrm{m}(1 \mathrm{~h}), 420 \mu \mathrm{m}(2 \mathrm{~h}), 170 \mu \mathrm{m}(3 \mathrm{~h}), 85 \mu \mathrm{m}(4 \mathrm{~h})$, respectively 


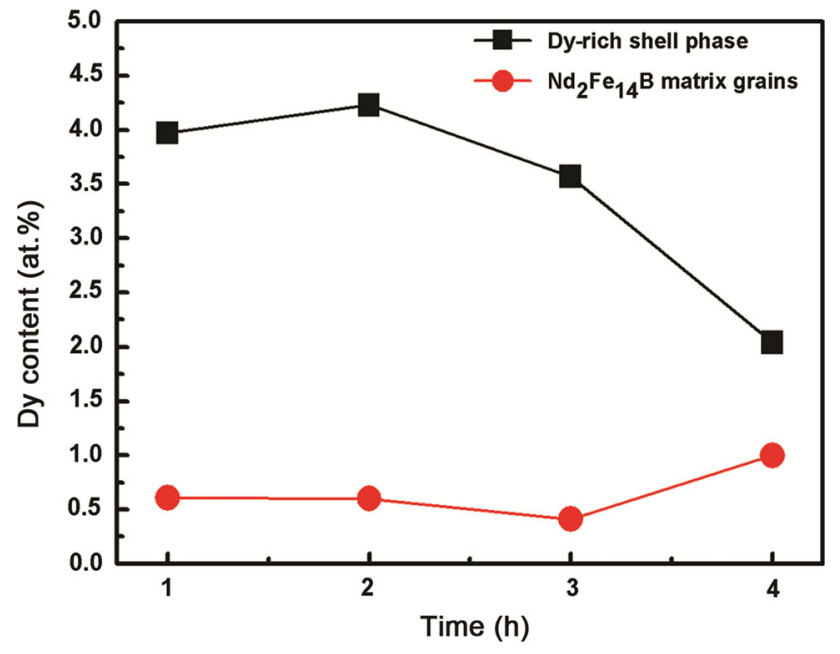

Fig. 5 Average Dy content after GBDP at $860^{\circ} \mathrm{C}$ for different time

where the core-shell structure nearly disappeared can be used to analyze the mechanism for the reduction in depth of the core-shell structure in GBDPed magnets heat-treated at $860{ }^{\circ} \mathrm{C}$ for 3 and $4 \mathrm{~h}$. It can be observed from Fig. 5 that the content of Dy in Dy-rich shell phase reached the peak at $2 \mathrm{~h}$ and then dropped down with the increase in heat treatment time. In contrast, the content of Dy in $\mathrm{Nd}_{2} \mathrm{Fe}_{14} \mathrm{~B}$ grains maintained steady at the time of 1-3 $\mathrm{h}$ and increased at $4 \mathrm{~h}$.

\subsection{Micromagnetic Simulation}

The demagnetizing curves of samples at $860{ }^{\circ} \mathrm{C}$ for 2 and $4 \mathrm{~h}$ were calculated for the model displayed in the insertion of Fig. 6. This model had a single grain with a size of $1000 \mathrm{~nm} \times 1000 \mathrm{~nm} \times 1000 \mathrm{~nm}$, and it presented a coreshell structure containing a core of $\left.\left(\mathrm{Nd}_{1-y} \mathrm{Dy}\right)_{2}\right)_{2} \mathrm{Fe}_{14} \mathrm{~B}$ and a

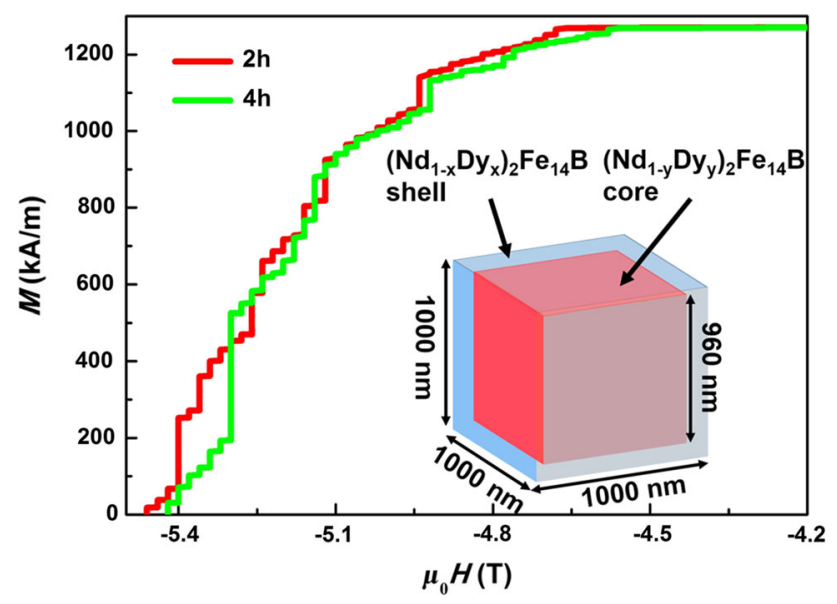

Fig. 6 Calculated demagnetization curves for GBDPed samples at $860{ }^{\circ} \mathrm{C}$ for 2 and $4 \mathrm{~h}$, respectively, based on the micromagnetic simulation model inserted shell of $\left(\mathrm{Nd}_{1-x} \mathrm{Dy}_{x}\right)_{2} \mathrm{Fe}_{14} \mathrm{~B}$. It should be noted that the size of the micromagnetic model is slightly smaller than the actual grain size in our model on account of computational limitations of micromagnetic simulations; however, it is worth noting that the whole model is on the microscale so that it can still be helpful for developing a qualitative understanding to the case in our study. The values of $x$ and $y$ were the Dy concentration measured by EDS in the Dyrich shell phase (brighter phase in Fig. 4, $x=4.23$ at. $\%$ at $2 \mathrm{~h}$ or 2.04 at.\% at $4 \mathrm{~h}$ ) and core phase (darker phase in Fig. $4, y=0.6$ at. $\%$ at $2 \mathrm{~h}$ or 1 at. $\%$ at $4 \mathrm{~h}$ ). The material parameters of both $\left(\mathrm{Nd}_{1-y} \mathrm{Dy}_{y}\right)_{2} \mathrm{Fe}_{14} \mathrm{~B}$ and $\left(\mathrm{Nd}_{1-x} \mathrm{Dy}\right)_{2-}$ $\mathrm{Fe}_{14} \mathrm{~B}$ phase were regarded as a linear function between $\mathrm{Nd}_{2} \mathrm{Fe}_{14} \mathrm{~B}$ and $\mathrm{Dy}_{2} \mathrm{Fe}_{14} \mathrm{~B}$. The micromagnetic simulation results show that the coercivity of the sample heat-treated for $2 \mathrm{~h}$ is higher than that for $4 \mathrm{~h}$.

\section{Discussion}

In the present paper, commercial $\mathrm{Nd}-\mathrm{Fe}-\mathrm{B}$ sintered magnets were treated by GBDP with $\mathrm{Dy}_{70} \mathrm{Cu}_{30}$ alloy under different heat treatment conditions. Experimental results show that both the coercivity and thermal stabilities of the diffusion-processed magnets were enhanced compared with the original magnet. Meanwhile, the introduction of Dy resulted in a slight decrease in remanence of the magnet. It has been widely accepted that the coercivity of the diffusion-processed magnet is improved mainly on account of the continuous grain boundary phase and the core-shell structure [22, 23], which can lead to the sufficient decoupling of the matrix grains $[24,25]$. The decrease in remanence is primarily caused by the substitution of Dy for $\mathrm{Nd}$ in the main phase. The improved thermal stability should be attributed to the optimized microstructure and the increased intrinsic property $H_{A}$ [26]. Our experimental results are consistent with the above considerations. Moreover, it was found that the heat treatment time has a significant effect on the depth of the core-shell structure, which may cause the variation of coercivity in the GBDPed magnet. Below, some important points in the experiments are discussed.

Coercivity of $\mathrm{Nd}-\mathrm{Fe}-\mathrm{B}$ magnets is a structure-sensitive parameter. The diffusion of Dy element and the pure heat treatment will simultaneously affect the microstructure of the GBDPed Nd-Fe-B magnets. Without considering the grain boundary diffusion, the heat treatment still has a significant effect on the microstructure of $\mathrm{Nd}-\mathrm{Fe}-\mathrm{B}-$ based magnets and the highest coercivity usually corresponds to an optimal heat treatment [27, 28]. Because the original material is a commercial magnet which has been heattreated under the optimal condition before GBDP, the additional heat treatment states we set would greatly affect 
the grain boundaries, deteriorating the magnetic properties of the reference samples, as shown in Fig. 2a. It can be seen that there is no evident rule of the coercivity changing with the heat treatment temperature or time. On the other side, the diffusion of Dy-Cu alloy is beneficial to the coercivity improvement owing to the formation of $\mathrm{Nd}_{2}$ $\mathrm{Fe}_{14} \mathrm{~B} /(\mathrm{Nd}, \mathrm{Dy})_{2} \mathrm{Fe}_{14} \mathrm{~B}$ core-shell structure, which has been confirmed by much research $[12,29,30]$ as well as our paper here. Therefore, taking account of both grain boundary diffusion and pure heat treatment, the combined effect would lead to the fluctuation of coercivity in the GBDPed magnets because of the inhomogeneous distribution of grain boundary phase which was affected by the heat treatment.

Figure 4 indicates that instead of a linear increase in the visible Dy-rich shell phase, the samples GBDPed for 3 and $4 \mathrm{~h}$ presented unusual shorter depth of Dy-rich shell with only about 100 and $70 \mu \mathrm{m}$, respectively. The mechanism may be explained according to Fig. 5. The content of Dy in $\mathrm{Nd}_{2} \mathrm{Fe}_{14} \mathrm{~B}$ grains increased while that in Dy-rich shell decreased when the heat treatment time exceeded $3 \mathrm{~h}$. The Dy element diffused further from the Dy-rich shell phase into the $\mathrm{Nd}_{2} \mathrm{Fe}_{14} \mathrm{~B}$ matrix phase, which resulted in the continuous substitution among the interface. Therefore, there was no obvious visible contrast in SEM images in deep area, and we could only observe the brighter coreshell structure from a short distance from the surface.

Figure 6 indicates the demagnetization curves of two samples heat-treated for 2 and $4 \mathrm{~h}$, respectively. The steps appeared in the demagnetization curves are mainly because of the multi-domain structure of the micrograin. So, the magnetic moments reversed at different intensities of applied field. It is shown that the coercivity of 2-h sample is higher than 4-h sample. The total Dy concentration of the model is expressed as

$C_{\text {Dy }}=x \varphi_{\text {shell }}+y \varphi_{\text {core }}$.

where $\varphi_{\text {shell }}(11.5 \%)$ and $\varphi_{\text {core }}(88.5 \%)$ are the volume fraction of the shell and core phase in the simulation model, respectively. The values of $x$ and $y$ are the Dy concentration in the Dy-rich shell phase and core phase as shown in Fig. 5. According to Eq. (1), the total Dy concentration in 4-h sample (1.12 at.\%) was larger than that in 2-h sample (1.02 at.\%). Therefore, the effect of harder Dyrich shell on the coercivity of sample is stronger than the relatively homogeneous structure with even higher Dy concentration. Thus, the reduction in coercivity for the samples GBDPed with heat treatment time over $2 \mathrm{~h}$ is very likely due to the depth of core-shell structure. The coreshell structure has a higher magnetocrystalline anisotropy field, which can suppress the nucleation of reverse magnetic domains on the surface of the $\mathrm{Nd}_{2} \mathrm{Fe}_{14} \mathrm{~B}$ grains during the magnetic reversal process.

\section{Conclusions}

In this work, we proposed the effect of heat treatment time on the microstructure and coercivity of sintered $\mathrm{Nd}-\mathrm{Fe}-\mathrm{B}$ magnets. Sintered Nd-Fe-B magnets were coated with Dy- $\mathrm{Cu}$ alloy powders and subsequently given a diffusion treatment. It was found that the room temperature coercivity and temperature stability of the diffusion-processed $\mathrm{Nd}-\mathrm{Fe}-\mathrm{B}$ magnets can be effectively improved. For the GBDPed magnet heat-treated at $860^{\circ} \mathrm{C}$, when the heat treatment time is not more than $2 \mathrm{~h}$, Dy mainly diffuses into the magnet through liquid grain boundaries phases to form the $(\mathrm{Nd}, \mathrm{Dy})_{2} \mathrm{Fe}_{14} \mathrm{~B}$ shell; when the heat treatment time is more than $2 \mathrm{~h}$, the diffusion of Dy from the Dy-rich shell into the $\mathrm{Nd}_{2} \mathrm{Fe}_{14} \mathrm{~B}$ grains would dominate in the process. Micromagnetic simulation confirmed that the core-shell structure with high Dy content in shell phase and low Dy content in core phase was beneficial to coercivity.

Acknowledgements This work was supported by the Guangdong Natural Science Foundation (2016A030313502), the Fundamental Research Funds for the Central Universities, SCUT (2015ZZ066), the Guangdong Science and Technology Planning Project (2013B090500115), and the Open Research Fund of Guangdong Key Laboratory (B7140010). We also thank Dr. Eric J. Payton (AFRL/ RXCM) for proofreading this manuscript.

\section{References}

[1] J.J. Croat, J.F. Herbst, R.W. Lee, F.E. Pinkerton, J. Appl. Phys. 55, 2078 (1984)

[2] M. Sagawa, S. Fujimura, N. Togawa, H. Yamamoto, Y. Matsuura, J. Appl. Phys. 55, 2083 (1984)

[3] H. Sepehri-Amin, T. Ohkubo, K. Hono, J. Appl. Phys. 107, 09A745 (2010)

[4] H. Sepehri-Amin, T. Ohkubo, K. Hono, Acta Mater. 61, 1982 (2013)

[5] Z. Samardžija, P. McGuiness, M. Soderžnik, S. Kobe, M. Sagawa, Mater. Charact. 67, 27 (2012)

[6] K. Hirota, T. Hirota, M. Minowa, J. Honshima, J. Alloys Compd. 42, 2909 (2006)

[7] F. Xu, J. Wang, X. Dong, L. Zhang, J.J. Wu, J. Alloys Compd. 509, 7909 (2011)

[8] M. Soderžnik, M. Korent, K. Žagar Soderžnik, M. Katter, K. Üstüner, S. Kobe, Acta Mater. 115, 278 (2016)

[9] K.H. Bae, S.R. Lee, H.J. Kim, M.W. Lee, T.S. Jang, J. Appl. Phys. 118, 203902 (2015)

[10] T. Ma, X. Wang, X. Liu, C. Wu, M. Yan, J. Phys. D Appl. Phys. 48, 215001 (2015)

[11] S. Lee, J. Kwon, H.R. Cha, K.M. Kim, H.W. Kwon, J. Lee, D. Lee, Met. Mater. Int. 22, 340 (2016)

[12] M. Tang, X. Bao, K. Lu, L. Sun, J. Li, X. Gao, Scr. Mater. 117, 60 (2016)

[13] H. Sepehri-Amin, J. Liu, T. Ohkubo, K. Hioki, A. Hattori, K. Hono, Scr. Mater. 69, 647 (2013)

[14] H. Sepehri-Amin, T. Ohkubo, S. Nagashima, M. Yano, T. Shoji, A. Kato, T. Schrefl, K. Hono, Acta Mater. 61, 6622 (2013) 
[15] X. Tang, R.J. Chen, W.Z. Yin, C.X. Jin, D. Lee, A. Yan, Appl. Phys. Lett. 107, 202403 (2015)

[16] N. Watanabe, M. Itakura, M. Nishida, J. Alloys Compd. 557, 1 (2013)

[17] Z. Wang, J. Ju, J. Wang, W. Yin, R. Chen, M. Li, C. Jin, X. Tang, D. Lee, A. Yan, Sci. Rep. 6, 38335 (2016)

[18] S. Sawatzki, C. Kübel, S. Ener, O. Gutfleisch, Acta Mater. 115, 354 (2016)

[19] M.J. Donahue, D.G. Porter, in OOMMF user's guide, version 1.0, Nat. Inst. Standards and Technology, Gaithersburg, MD, Tech. Rep. NISTIR 6376. USA, 1999

[20] M. Sagawa, S. Fujimura, H. Yamamoto, Y. Matsuura, S. Hirosawa, J. Appl. Phys. 57, 4094 (1985)

[21] S. Hirosawa, Y. Matsuura, H. Yamamoto, S. Fujimura, M. Sagawa, H. Yamauchi, J. Appl. Phys. 59, 873 (1986)

[22] N. Oono, M. Sagawa, R. Kasada, H. Matsui, A. Kimura, J. Magn. Magn. Mater. 323, 297 (2011)
[23] K. Löewe, C. Brombacher, M. Katter, O. Gutfleisch, Acta Mater. 83, 248 (2015)

[24] L.Q. Yu, J. Zhang, S.Q. Hu, Z.D. Han, M. Yan, J. Magn. Magn. Mater. 320, 1427 (2008)

[25] M. Yan, L.Q. Yu, W. Luo, W. Wang, W.Y. Zhang, Y.H. Wen, J. Magn. Magn. Mater. 301, 1 (2006)

[26] L. Liu, H. Sepehri-Amin, T. Ohkubo, M. Yano, A. Kato, T. Shoji, K. Hono, J. Alloys Compd. 666, 432 (2016)

[27] Y.H. Liu, S. Guo, R.J. Chen, D. Lee, A. Yan, IEEE Trans. Magn. 47, 3270 (2011)

[28] K. Skotnicová, G.S. Burkhanov, Y. Koshkidko, D. Růžička, T. Čegan, J. Ćwik, N.B. Kolchugina, A.A. Lukin, O. Životský, K. Hrabovská, Metalurgija 55, 621 (2016)

[29] W.B. Cui, Y.Q. Fu, T. Liu, G.J. Li, Q. Wang, J. Alloys Compd. 686, 101 (2016)

[30] K. Loewe, D. Benke, C. Kübel, T. Lienig, K.P. Skokov, O. Gutfleisch, Acta Mater. 124, 421 (2017) 